\title{
Determinants of effective ventilation during nasal intermittent positive pressure ventilation
}

\author{
V.F. Parreira*, V. Jounieaux+, P. Delguste*, G. Aubert**, M. Dury**, D.O. Rodenstein*
}

Determinants of effective ventilation during nasal intermittent positive pressure ventilation. V.F. Parreira, V. Jounieaux, P. Delguste, G. Aubert, M. Dury, D.O. Rodenstein. CERS Journals Ltd 1997.

ABSTRACT: Our aim was to verify in healthy subjects submitted to nasal intermittent positive pressure ventilation (nIPPV) with a volumetric ventilator on controlled mode, whether changes in ventilator settings (delivered tidal volume $(V T)$, respiratory frequency $(f R)$ and inspiratory flow $\left(V^{\prime} I\right)$ ) could influence effective minute ventilation $\left(V^{\prime} \mathrm{E}\right)$, thus allowing identification of the settings resulting in the highest $V^{\prime} E$ during nIPPV. We then compared these experimentally obtained "best" settings to those obtained retrospectively in a group of patients submitted to long-term nIPPV for clinical reasons.

We studied 10 healthy subjects awake and asleep, and 33 patients with restrictive ventilatory disorders.

Changes in delivered $V^{\prime} I$ (for a constant delivered $V T$ and $f \mathrm{R}$ ) led to significant changes in $V^{\prime} E$. $V^{\prime} \mathrm{E}$ was significantly higher when a given delivered $V^{\prime} \mathrm{E}$ was obtained using higher $f \mathrm{R}$ and lower $V \mathrm{~T}$ than when it was obtained using lower delivered $f \mathrm{R}$ and higher $V \mathrm{~T}$. Increases in $f \mathrm{R}$ generally resulted in increases in $V^{\prime} \mathrm{E}$.

The "best" settings derived from these results were: $V \mathrm{~T}: 13 \mathrm{~mL} \cdot \mathrm{kg}^{-1}$ of body weight; $f \mathrm{R}: 20$ breaths $\mathrm{min}^{-1}$ and $V^{\prime} \mathrm{I}: 0.56-0.85 \mathrm{~L} \cdot \mathrm{s}^{-1}$. The corresponding average values found in the patient group were: delivered $V \mathrm{~T}: 14 \mathrm{~mL} \cdot \mathrm{kg}^{-1} ; f \mathrm{R}: 23$ breaths. $\mathrm{min}^{-1}$ and delivered $V^{\prime}$ I: $0.51 \mathrm{~L} \cdot \mathrm{s}^{-1}$.

Changes in minute ventilation resulting from modifications in ventilator settings can be attributed to the glottic response to mechanical influences. This leads to "ideal" settings quite different from the standard ones in intubated patients. Values derived from nasal intermittent positive pressure ventilation in healthy subjects seem to apply to patients submitted to long-term nasal intermittent positive pressure ventilation.

Eur Respir J 1997; 10: 1975-1982.
*Pneumology and **EEG Units, Cliniques Universitaires Saint-Luc, Université Catholique de Louvain, 1200 Brussels, Belgium. +Pneumology Unit, Centre Hospitalier Universitaire Sud, Amiens, France.

Correspondence: D.O. Rodenstein Service de Pneumologie

Cliniques Universitaires Saint-Luc Avenue Hippocrate, 10 B-1200 Bruxelles

Belgium

Keywords: Assisted ventilation home ventilation

noninvasive

respiratory support

restrictive ventilatory disorders ventilators

Received: January 71997

Accepted after revision July 11997

VFP is on leave from the University Federal of Minas Gerais, Belo Horizonte, Brazil. Sponsored by CNPq, Brasilia, Brazil.

Partly supported by grants No. 9.4547 .93 and 9.4530.95 from the Belgian Fonds de la Recherche Scientifique Médicale.
Intermittent positive pressure ventilation applied through a nasal mask (nIPPV) is increasingly used for the treatment of acute and chronic ventilatory and respiratory failure in patients with a variety of diseases [1-4].

In noninvasive ventilation, conceptual and terminological problems go hand in hand. When one refers to ventilation, or tidal volume $(V \mathrm{~T})$, one may be pointing to the ventilation (or $V \mathrm{~T}$ ) delivered by the ventilator, or ventilation (or $V \mathrm{~T}$ ) reaching the lungs of the patients. Since leaks are inevitable in noninvasive ventilation, the two concepts are not equal. In this report we will identify by the word "effective" all the measurements referring to the subjects, and by "delivered" those derived from the ventilator.

Surprisingly, noninvasive mechanical ventilation using volumetric ventilators remains, in 1997, more an art than a science. In contrast with the situation in intubated patients [5], there are no published guidelines concerning the best implementation of ventilator parameters (delivered $V \mathrm{~T}$, delivered minute ventilation $\left(V^{\prime} \mathrm{E}\right)$, delivered respiratory frequency $(f \mathrm{R})$, delivered inspiratory flow $\left(V^{\prime} \mathrm{I}\right)$, inspiratory/expiratory time ratio $\left.(t \mathrm{I} / t \mathrm{E})\right)$, so that clinicians usually adjust such parameters by a trial and error process; however, there seems to be no agreement (at least based on sound experimental data) on the adjustment of ventilator parameters $[6,7]$.

In patients with restrictive ventilatory defects under nIPPV, we have observed periods with apnoeas, sometimes longer than $1 \mathrm{~min}$. We have postulated that these apnoeas were not primarily due to leaks but to complete glottic closure, resulting in secondary leaks [8]. Subsequently, we have shown in healthy volunteers under nIPPV using volumetric ventilators, that glottic aperture represents the main factor regulating the effective ventilation reaching the lungs $[9,10]$. Increases in delivered $V^{\prime} \mathrm{E}$ lead to glottic narrowing and to a decrease in the proportion of $V^{\prime} \mathrm{E}$ effectively reaching the lungs, and can even result in complete glottic closure with an ensuing apnoea and the appearance of mouth leaks. Glottic aperture is influenced by sleep, $\mathrm{CO}_{2}$ levels and, probably, mechanical factors such as delivered $V$ 'I [911]. It might thus be possible to influence the degree of glottic narrowing during nIPPV by modifying the settings of the ventilator. By doing this, one may favour 
glottic widening and, therefore, increase effective $V \mathrm{~T}$ and minute ventilation $\left(V^{\prime} \mathrm{E}\right)$.

In the first part of this study we investigated in awake and asleep normal subjects the effects of systematic changes in $V \mathrm{~T}, V^{\prime} \mathrm{E}$, delivered $f_{\mathrm{R}}$ and delivered $V^{\prime} \mathrm{I}$ on effective $V \mathrm{~T}$ and $V^{\prime} \mathrm{E}$ (i.e. the $V^{\prime} \mathrm{E}$ calculated from the $V \mathrm{~T}$ effectively reaching the lungs), with the goal of establishing the best way to perform nIPPV using volumetric ventilators in the controlled mode (i.e. to attain the higher effective $V^{\prime} \mathrm{E}$ ). In the second part, in order to verify whether our findings in normal subjects bore any relevance to patients, we performed a retrospective clinical study of ventilator settings in a group of patients submitted to long-term home nIPPV, who were put on nIPPV before the analysis of our experimental data in normal subjects.

\section{Materials and methods}

\section{Experimental study}

Ten healthy medical students who had never smoked (six males and four females), age range 20-26 yrs, body mass index: $22 \pm 2.2$ (SD) (range 20-28) $\mathrm{kg} \cdot \mathrm{m}^{-2}$, without evidence of respiratory diseases, were studied during nIPPV using a volumetric ventilator.

The protocol of the study was approved by the Ethics Committee of the hospital. Subjects were habituated to mechanical ventilation during two previous training sessions where they learnt to relax their ventilatory muscles $[12,13]$. All subjects gave written informed consent and received financial remuneration for their participation in the study.

Signals and recording equipment. The electroencephalogram (EEG), electro-oculogram (EOG) and submental chin electromyogram (EMG) were obtained from surface electrodes using standard techniques [14]. The EMG of the diaphragm muscle (EMGdi) was obtained from surface electrodes placed around the fifth intercostal space. The EMGdi signal was filtered between 30 and $3,000 \mathrm{~Hz}$, but not rectified or integrated. The electrocardiogram was obtained from two surface electrodes placed on the chest. Mouth air flow was assessed with one thermocouple in front of the mouth.

Effective $V \mathrm{~T}$, i.e. the $V \mathrm{~T}$ actually reaching the lungs, was obtained by respiratory inductive plethysmography (Respitrace, Ambulatory Monitoring, Ardsley, NY, USA) calibrated with the isovolume technique. The accuracy of measurement of $V \mathrm{~T}$ by inductive plethysmography is satisfactory as long as the body position remains constant after the isovolume manoeuvre $[15,16]$. The sum of the thorax and abdominal signals was calibrated against a water-sealed spirometer. Mask pressure ( $P$ mask) was measured from a port in the nasal mask with a Honeywell transducer (type 162 PC 01 D, Micro Switch Division, Honeywell, Freeport, IL, USA) calibrated with an alcoholfilled manometer. All these signals were recorded with a digital acquisition system (OSG Brainlab, Antwerp, Belgium), as described previously [11].

Procedure. Each subject was asked to remain awake during the night preceding the study. Subjects lay comfor- tably in bed, in the supine position, with pillows on both sides securing a fixed position and avoiding any shift of the body during the night. Electrodes and plethysmography were then applied and nIPPV was started. The first 10-15 min of recordings were not retained for analysis.

The ventilator used was the EOLE 2A (SAIME, Savignele-Temple, France), which is a constant-flow volumetric ventilator with the following operating ranges: delivered $V \mathrm{~T}: 160-1,350 \mathrm{~mL} ; \mathrm{R}$ : $8-44$ breaths. $\mathrm{min}^{-1}$; $\mathrm{tI} / \mathrm{tE}: 1 / 1-$ $1 / 3.5$. Subjects were ventilated either with a constant delivered $V \mathrm{~T}$ (delivered $f \mathrm{R}$ and/or $t \mathrm{I} / t \mathrm{E}$ being systematically varied); or with a constant delivered $V^{\prime} \mathrm{I}$ and $V \mathrm{~T}(f \mathrm{R}$ being changed); or with a constant delivered $V$ 'E, (delivered $V \mathrm{~T}$ and delivered $f \mathrm{R}$ being modified). Table 1 gives the details of the different settings used throughout the experiments.

This allowed us to compare: 1) the steps with the same delivered $V \mathrm{~T}$ and $f \mathrm{R}$ values (thus with the same delivered $V^{\prime} \mathrm{E}$ ) but at different delivered $V^{\prime}$ I (steps 1 and $2,3-5$, and 7 and 8 in table 1);2) the steps with the same delivered $V \mathrm{~T}$ and $V^{\prime} \mathrm{I}$, but at different $f \mathrm{R}$ values, thus with increasing delivered $V^{\prime} \mathrm{E}$, (steps 2, 4 and 7, and steps 5 and 8 in table 1); and 3) the steps with the same delivered $V^{\prime}$ E but with different delivered $V \mathrm{~T}$ and $f \mathrm{R}$ values (steps 2 and 6 in table 1).

In other words, by doing this we could study the separate effects on effective $V^{\prime}$ E of delivered $V^{\prime}$ I, delivered $V^{\prime} \mathrm{E}$ and delivered $V \mathrm{~T}$, the three main parameters regulating volumetric ventilators.

The records were made during wakefulness and sleep. The wakefulness data were obtained at the beginning or the end of the records depending on whether the subjects fell rapidly asleep or not. All subjects were studied for at least $4 \mathrm{~h}$ and the recordings were ended when the subjects stayed awake for more than $45 \mathrm{~min}$. Ventilator parameters were modified after at least $1 \mathrm{~min}$ of good quality recordings of stable state for each setting.

Measurements. Sleep/wake status was scored according to standard criteria [14]. Movement arousals were defined as the reappearance of an alpha rhythm in the EEG during a sleep epoch, accompanied by an increase in chin EMG activity lasting for more than 2 s [17]. Sleep efficiency was defined as the percentage of sleep time with respect to total recording time. Periods preceded

Table 1. - Ventilator settings used for each step during intermittent positive pressure ventilation applied through the nose in healthy subjects

\begin{tabular}{cccccc}
\hline Step* $^{*} \begin{array}{c}f \mathrm{R} \\
\text { breaths·min }\end{array}$ & $\begin{array}{c}V \mathrm{~T} \\
\mathrm{~mL}\end{array}$ & $t \mathrm{t} / t \mathrm{E}$ & $\begin{array}{c}V^{\prime} \mathrm{E} \\
\mathrm{L} \cdot \mathrm{min}^{-1}\end{array}$ & $\begin{array}{c}V^{\prime} \mathrm{I} \\
\mathrm{L} \cdot \mathrm{s}^{-1}\end{array}$ \\
\hline 1 & 15 & 850 & $1 / 1$ & 12.7 & 0.42 \\
2 & 15 & 850 & $1 / 3$ & 12.7 & 0.85 \\
3 & 20 & 850 & $1 / 1$ & 17.0 & 0.56 \\
4 & 20 & 850 & $1 / 2$ & 17.0 & 0.85 \\
5 & 20 & 850 & $1 / 3$ & 17.0 & 1.21 \\
6 & 11 & 1160 & $1 / 3$ & 12.7 & 0.89 \\
7 & 27 & 850 & $1 / 1.2$ & 22.9 & 0.85 \\
8 & 27 & 850 & $1 / 2$ & 22.9 & 1.21 \\
\hline
\end{tabular}

$f \mathrm{R}$ : respiratory frequency; $V \mathrm{~T}$ : tidal volume; $t \mathrm{t} / t \mathrm{E}$ : inspiratory/ expiratory time ratio; $V^{\prime} \mathrm{E}$ : minute ventilation; $V^{\prime} \mathrm{I}$ : inspiratory flow. *: step numbers refer to different respirator settings. 
by at least $1 \mathrm{~min}$ of stable sleep/wake state, and absence of swallowing and diaphragmatic and phasic chin EMG activity were considered for analysis of steady state levels. Stages 3 and 4 of nonrapid eye movement (NREM) sleep were analysed together.

For each period, all individual values for inspiratory $V \mathrm{~T}$, inspiratory time $(t \mathrm{I})$, total ventilatory cycle duration (tot), and $P$ mask, were obtained directly via the digital acquisition system. We calculated breath-by-breath, $f \mathrm{R}$ from $t$ tot $\left(f \mathrm{R}=60 / t_{\text {tot }}\right)$; effective $V^{\prime} \mathrm{E}$ from $V \mathrm{~T}$ and $f \mathrm{R}$; effective mean $V^{\prime}$ I (i.e. the mean $V^{\prime}$ I of the delivered $V$ T actually reaching the lungs), from $V \mathrm{~T}$ and $t \mathrm{I}$ and inspiratory resistance $(R \mathrm{I})$ calculated from the peak $P$ mask and mean effective $V^{\prime}$ I.

Data are presented as the mean \pm standard deviation (SD). Group comparisons were performed by Wilcoxon test, a p-value of less than 0.05 was considered significant. Intra-individual comparisons were performed with the unpaired Student's t-test. Using the Bonferroni's correction [18], a p-value of less than 0.001 was considered significant.

\section{Clinical study}

Thirty three patients ( 17 females and 16 males), median age 35 (range 6-74) yrs, weight 51 18 (range 15-91) $\mathrm{kg}$, height $1.56 \pm 0.3$ (range $0.78-1.96$ ) $\mathrm{m}$, body mass index $21 \pm 6$ (range $9.8-34.3$ ) $\mathrm{kg} \cdot \mathrm{m}^{-2}$, were studied retrospectively. All patients, except one, presented with a chronic respiratory insufficiency, secondary to restrictive ventilatory disorders. Their diagnoses were: myopathy $(n=16)$, neuropathy $(n=8)$, chest-wall deformities $(n=7)$, primary alveolar hypoventilation $(n=1)$ and chronic obstructive pulmonary disease (COPD) $(n=1)$. Home ventilation, performed in all cases with volumetric ventilators used in the controlled mode, was initiated in patients who suffered from acute exacerbations of respiratory failure, or in the presence of repeated episodes of pulmonary infections despite maximal treatment, after objectivation of sleep-related falls in arterial oxygen saturation $\left(\mathrm{Sa}_{\mathrm{a}} \mathrm{O}_{2}\right)$ during polysomnography.

Home ventilation was started after a 1 week training period in hospital. During this period, the patient's respiratory comfort was the main objective. The delivered $f \mathrm{R}$ was fixed slightly above the patient's own $f \mathrm{R}$, delivered $V \mathrm{~T}$ at a level the patient felt comfortable with, and $t \mathrm{I} / t \mathrm{E}$ was fixed at $1 / 1$ to minimize the insufflation pressures and consequent mask leaks. Initially, nIPPV was used during the day and progressively also during the night. In the last night in hospital a polysomnography was performed to determine the best settings of the ventilator during sleep. The parameters used as a guide to adjust the ventilator settings were: a good quality of sleep (sleep stability and the presence of all NREM sleep stages and rapid eye movement (REM) sleep); the highest possible levels of $\mathrm{Sa}_{2} \mathrm{O}_{2}$ without oxygen addition; and complete or almost complete disappearance of the surface EMG signal of respiratory muscles. During polysomnography, delivered $f \mathrm{R}, V \mathrm{~T}$ and $t \mathrm{t} / t \mathrm{E}$ were progressively increased or decreased as needed to achieve the best possible results. Measurements of effective $V \mathrm{~T}$ or ventilation reaching the lungs were never performed.

\section{Results}

\section{Experimental study}

All subjects presented stable periods (as described in Materials and methods), during both wakefulness and sleep. All subjects had all NREM sleep stages, and six of the 10 subjects had REM sleep, but sleep architecture was abnormal with excess stage 1 NREM sleep. Table 2 shows their sleep architecture. Sleep efficiency was poor, with a mean value of $54.9 \pm 11.1 \%$, range $31-$ $72 \%$, but without excessive sleep fragmentation (movement arousals $6.1 \pm 4.6$ events $\cdot h^{-1}$ ) [17].

Table 3 shows the number of subjects in whom data were available, showing steady-state periods, for each step, during wakefulness, NREM and REM sleep. For the group as a whole, 156 periods of steady state were analysed: 51 periods during wakefulness, 89 during NREM sleep and 16 during REM sleep. The mean number of periods per subject was $15.6 \pm 3.1$. The average length of steady-state periods was $2.18 \pm 0.2 \mathrm{~min}$. A total of 6,186 breaths were analysed with a mean of $618 \pm 128$ breaths per subject.

Table 2. - Sleep architecture for 10 subjects during intermittent positive pressure ventilation applied through the nose using a volumetric ventilator

\begin{tabular}{|c|c|c|c|c|c|c|c|c|c|c|}
\hline & \multicolumn{10}{|c|}{ Subject number } \\
\hline & 1 & 2 & 3 & 4 & 5 & 6 & 7 & 8 & 9 & 10 \\
\hline TRT $\min$ & 328 & 290 & 436 & 223 & 371 & 294 & 410 & 449 & 380 & 400 \\
\hline TST $\min$ & 102 & 208 & 282 & 143 & 199 & 151 & 236 & 205 & 180 & 242 \\
\hline \multicolumn{11}{|l|}{ NREM time $\%$} \\
\hline Stage 1 & 48 & 13 & 21 & 5 & 16 & 15 & 22 & 28 & 14 & 8 \\
\hline Stage 2 & 39 & 58 & 37 & 46 & 42 & 35 & 46 & 49 & 74 & 47 \\
\hline Stage 3 & 3 & 5 & 31 & 14 & 17 & 8 & 15 & 8 & 6 & 17 \\
\hline Stage 4 & 10 & 24 & 9 & 27 & 23 & 30 & 11 & 16 & 6 & 11 \\
\hline REM time \% & - & - & 3 & 7 & 3 & 12 & 5 & - & - & 17 \\
\hline MA events $\cdot h^{-1}$ & 14 & 15 & 5 & 2 & 5 & 5 & 4 & 1 & 8 & 2 \\
\hline Sleep efficiency \% & 31 & 72 & 65 & 64 & 54 & 51 & 58 & 46 & 47 & 61 \\
\hline
\end{tabular}

TRT: total recording time; TST: total sleep time; NREM: nonrapid eye movement; REM: rapid eye movement; MA: movement arousals. Subjects 2, 3, 9 and 10 were female. 
Effects of changes in delivered $\mathrm{V}^{\prime} \mathrm{I}$ with constant delivered $\mathrm{V} T$, delivered $\mathrm{f} R$, and delivered $\mathrm{V}^{\prime} E$ on effective $V^{\prime} E$. For the group of awake subjects, increases in delivered $V^{\prime}$ I from 0.42 to $0.85 \mathrm{~L} \cdot \mathrm{s}^{-1}$ (steps 1 and 2) or from 0.56 to $0.85 \mathrm{~L} \cdot \mathrm{s}^{-1}$ (steps 3 and 4) resulted in significant increases in $V^{\prime} \mathrm{E}$ (fig. 1). By contrast, further increases in delivered $V^{\prime}$ I to $1.21 \mathrm{~L} \cdot \mathrm{s}^{-1}$ (step 5) did not further mod-

Table 3. - Number of subjects that showed steadystate periods, for all studied steps

\begin{tabular}{lcccc}
\hline Step* & Waking & \multicolumn{2}{c}{ NREM stage } & REM \\
\cline { 3 - 5 } & & 2 & $3-4$ & \\
& $\mathrm{n}$ & $\mathrm{n}$ & $\mathrm{n}$ & $\mathrm{n}$ \\
\hline 1 & 9 & 8 & 8 & 3 \\
2 & 6 & 9 & 5 & 4 \\
3 & 8 & 7 & 6 & 2 \\
4 & 10 & 8 & 7 & 4 \\
5 & 6 & 6 & 4 & 2 \\
6 & 5 & 8 & 3 & 1 \\
7 & 5 & 6 & 3 & 0 \\
8 & 2 & 0 & 1 & 0 \\
\hline
\end{tabular}

*: step numbers refer to different respirator settings. For further definitions see legend to table 2 .

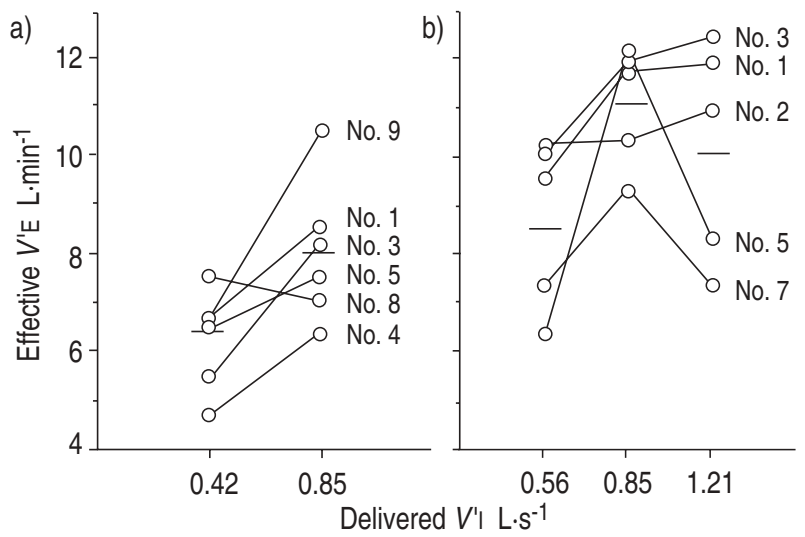

Fig. 1. - Mean individual values of effective minute ventilation $\left(V^{\prime} \mathrm{E}\right)$ during wakefulness at: a) two levels of delivered inspiratory flow $\left(V^{\prime} \mathrm{I}\right)$ (steps 1 and 2); and b) three levels of delivered $V^{\prime}$ I (steps 3, 4 and 5. Individual subjects are identified by number. Horizontal bars represent group mean values. For explanation of steps, see table 1, and for significance of changes, see text.
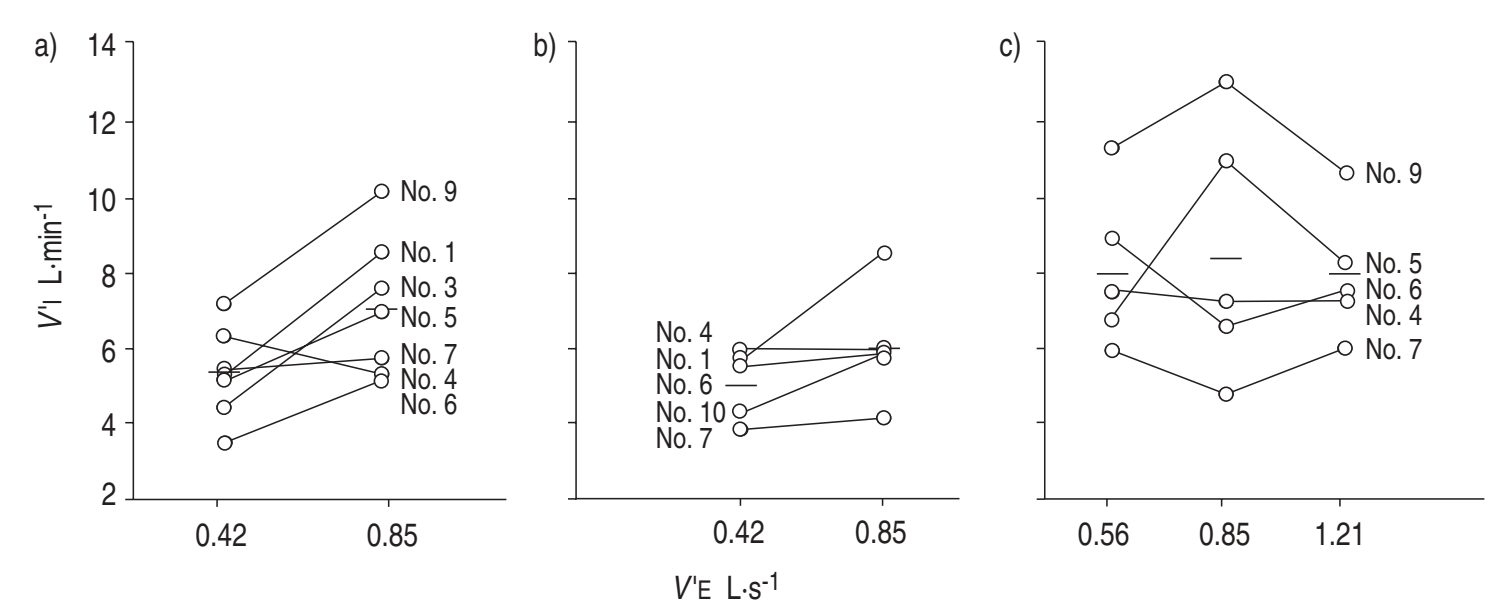

Effects of changes in $\mathrm{V}^{\prime}$ I on inspiratory resistance. During wakefulness, increases in delivered $V^{\prime}$ I from 0.42 to $0.85 \mathrm{~L} \cdot \mathrm{s}^{-1}$ (for a delivered $V^{\prime} \mathrm{E}$ of $12.7 \mathrm{~L} \cdot \mathrm{min}^{-1}$ ) resulted in significant decreases in $R \mathrm{I}$ (44 to $27 \mathrm{~cm} \mathrm{H} \mathrm{H}_{2} \mathrm{O} \cdot \mathrm{L}^{-1} \cdot \mathrm{s}^{-1}$, $\mathrm{p}=0.04$ for the group as a whole). Increases in $V^{\prime}$ I from 0.56 to $0.85 \mathrm{~L} \cdot \mathrm{s}^{-1}$ and from 0.56 to $1.21 \mathrm{~L} \cdot \mathrm{s}^{-1}$ (for a delivered $V^{\prime} \mathrm{E}$ of $\left.17 \mathrm{~L} \cdot \mathrm{min}^{-1}\right)$ resulted in decreases in $R \mathrm{I}$ in all subjects ( 45 to $29 \mathrm{cmH}_{2} \mathrm{O} \cdot \mathrm{L}^{-1} \cdot \mathrm{s}, \mathrm{p}=0.04$, and 45 to $30 \mathrm{cmH}_{2} \mathrm{O} \cdot \mathrm{L}^{-1} \cdot \mathrm{s}^{-1}, \mathrm{p}=0.04$, respectively). However, increases in delivered $V^{\prime}$ I from 0.85 to $1.21 \mathrm{~L} \cdot \mathrm{s}^{-1}$ of $V^{\prime} \mathrm{I}$ did not lead to any significant differences in $R \mathrm{I}$ (29 to $30 \mathrm{~cm} \cdot \mathrm{H}_{2} \mathrm{O} \cdot \mathrm{L}^{-1} \cdot \mathrm{s}^{-1}, \mathrm{p}=0.78$ ).

During stage 2 NREM sleep, increases in delivered $V^{\prime}$ I from 0.42 to $0.85 \mathrm{~L} \cdot \mathrm{s}^{-1}$ as well as from 0.56 to 0.85 $\mathrm{L} \cdot \mathrm{s}^{-1}$ resulted in significant decreases in $R \mathrm{I}(59$ to $32 \mathrm{~cm}$ $\mathrm{H}_{2} \mathrm{O} \cdot \mathrm{L}^{-1} \cdot \mathrm{s}, \mathrm{p}=0.01$, and 37 to $27 \mathrm{~cm} \mathrm{H}_{2} \mathrm{O} \cdot \mathrm{L}^{-1} \cdot \mathrm{s}, \mathrm{p}=0.04$. respectively). For increases in delivered $V^{\prime}$ I from 0.85 to $1.21 \mathrm{~L} \cdot \mathrm{s}^{-1}$ we observed no significant differences $(27$ to $30 \mathrm{cmH}_{2} \mathrm{O} \cdot \mathrm{L}^{-1} \cdot \mathrm{s}, \mathrm{p}=0.22$ ).

During stages 3 and 4 NREM sleep, increases in delivered $V^{\prime}$ I from 0.42 to $0.85 \mathrm{~L} \cdot \mathrm{s}^{-1}$ resulted in significant decreases in $R \mathrm{I}$ ( 54 to $34 \mathrm{~cm} \mathrm{H}_{2} \mathrm{O} \cdot \mathrm{L}^{-1} \cdot \mathrm{s}, \mathrm{p}=0.04$ ).

Effects of delivered $\mathrm{V} T$ and delivered $\mathrm{f} R$ with constant delivered $\mathrm{V}^{\prime} E$ and $\mathrm{V}^{\prime} I$ on effective $\mathrm{V}^{\prime} E$. Effective $V^{\prime} \mathrm{E}$ was significantly higher, for a given delivered $V^{\prime} \mathrm{E}$, when the delivered $V \mathrm{~T}$ was lower and $f \mathrm{R}$ higher (steps 2 and 6 , fig. 3) both during wakefulness and stage 2 NREM sleep.

Effects of delivered $\mathrm{f} R$ and $\mathrm{V}^{\prime} E$ with a constant $\mathrm{V} T$ and $V^{\prime} I$ on effective V'E. During wakefulness $V^{\prime} \mathrm{E}$ significantly increased in step $4\left(f \mathrm{R}=20\right.$ breaths $\left.\cdot \mathrm{min}^{-1}\right)$ with respect to step $2\left(f \mathrm{R}=15\right.$ breaths $\left.\cdot \mathrm{min}^{-1}\right)$, but not in step 7 $\left(f R=27\right.$ breaths $\left.\cdot \mathrm{min}^{-1}\right)$ with respect to step 4 (fig. 4$)$. During stage 2 NREM sleep, $V^{\prime}$ E was significantly higher

Fig. 2. - Mean individual values of effective $V^{\prime}$ 'E at a) two levels of delivered $V^{\prime}$ I (steps 1 and 2) during stage 2 nonrapid eye movement (NREM) sleep; and b) two levels of delivered $V^{\prime}$ I (steps 1 and 2), during stages 3 and 4 NREM sleep; c) three levels of delivered $V$ 'I (steps 3, 4 and 5), during stage 2 NREM sleep. Horizontal bars represent group mean values. For definitions of abbreviations, and explanation of steps, see legend to figure 1 and table 2 . For explanation of steps, see table 1 , and for significance of changes see text. 
for steps 4 and 7 with respect to step 2 (fig. 4). Group comparisons were not possible for steps 4 and 7 during stage 2 NREM sleep.

Wakefulness versus sleep. Comparisons between wakefulness and sleep were available for all subjects. A total of 70 comparisons were performed. When comparing for a given step, effective ventilation was lower during sleep than during wakefulness in 51 comparisons. The reverse was true in nine cases; in the remaining 10 comparisons, no significant differences were found. Overall, when comparing within subjects, effective ventilation was lower during sleep or similar during wakefulness and sleep in seven subjects (42 comparisons). In the three remaining subjects, comparisons showed lower effective ventilation during sleep in 15 comparisons, similar data of effective ventilation in wakefulness and sleep in four cases, and higher effective ventilation during sleep in nine cases.

Periodic breathing. Two subjects showed periodic breathing during stages 1 and 2 NREM sleep only: eleven periods of periodic breathing were observed, for a total duration of $11 \mathrm{~min}$. Nine periods corresponded to settings of step 3 and two to settings of step 4 . The mean length of these periods was $60 \pm 15 \mathrm{~s}$, range $30-75 \mathrm{~s}$, representing 2.6 and $2.4 \%$ of total sleep time in the two subjects, respectively. Periodic breathing was characterized by successive cycles of waning and waxing of $V T$. Two types of event were observed. In the first type, increases in $V \mathrm{~T}$ were accompanied by changes in EEG activity (reappearance of $\alpha$ rhythm with or without EMGdi activation (one and five periods, respectively). In the second type, no change in sleep state, EEG activity or EMGdi was observed. Apnoeas were never observed.

\section{Clinical study}

The retrospective analysis was performed on patients started on nIPPV between November 1987 (the first

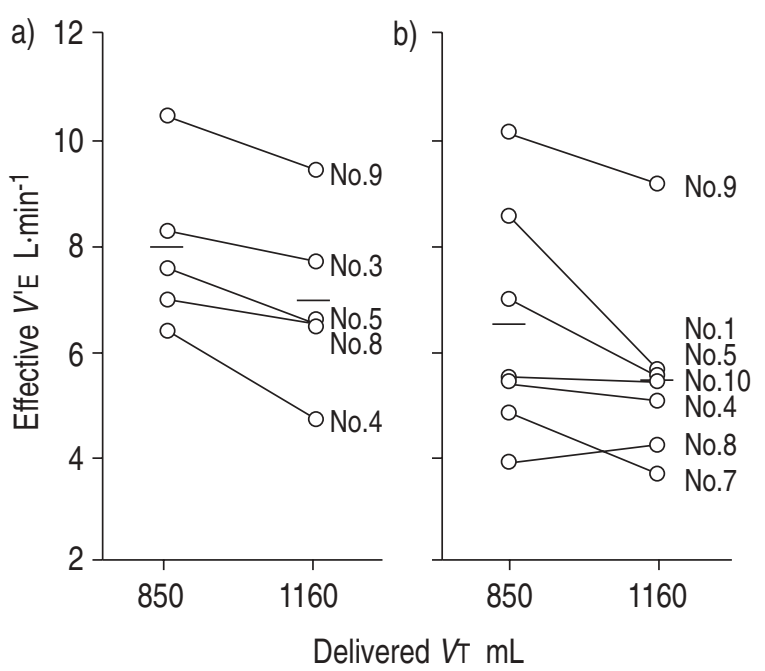

Fig. 3. - Mean individual values of effective $V^{\prime} E$ at two levels of delivered tidal volume $(V \mathrm{~T})$ (steps 2 and 6) during: a) wakefulness; and b) stage 2 nonrapid eye movement (NREM) sleep. Horizontal bars represent group mean values. For definitions, see legend to figure 1. For explanation of steps, see table 1, and for significance of changes, see text.
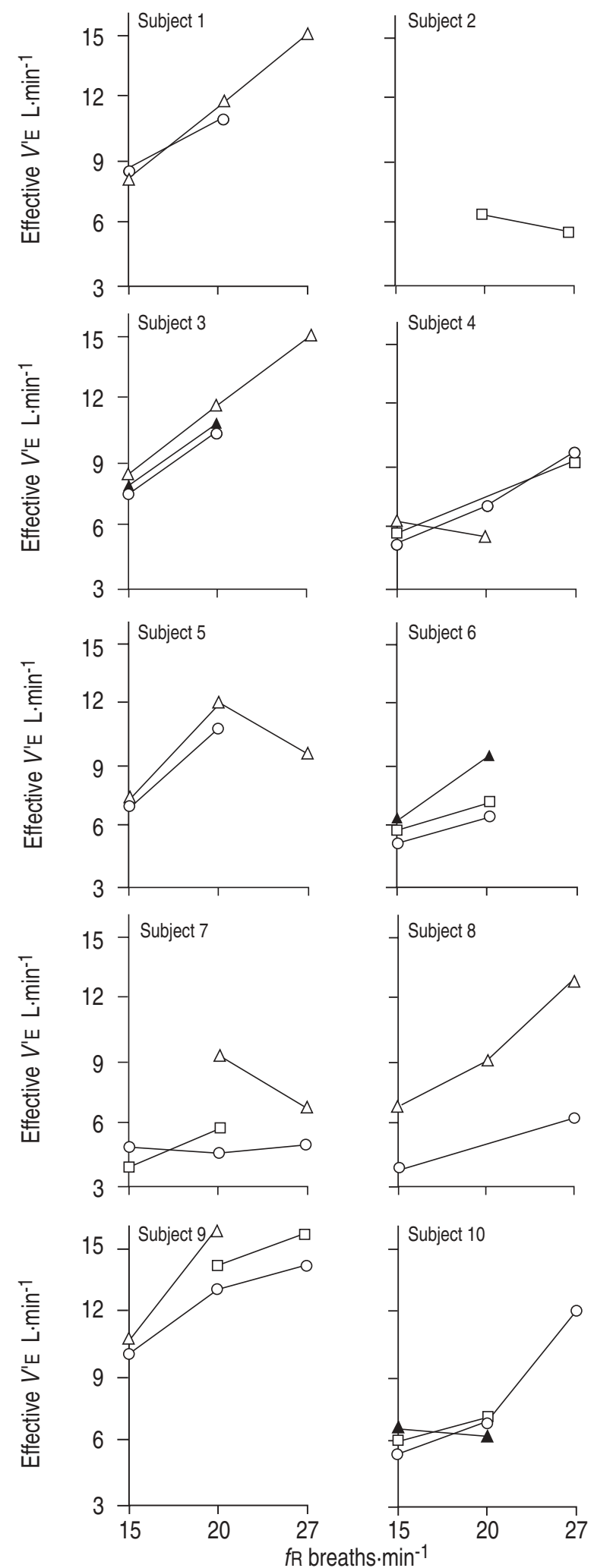

Fig. 4. - Mean individual data of effective $V^{\prime} \mathrm{E}$ at three levels of delivered respiratory frequency $(f \mathrm{R})$ (steps 2,4 and 7 ), during wakefulness, nonrapid eye movement (NREM) and rapid eye movement (REM) sleep in 10 subjects. $\Delta$ : wakefulness; O : stage 2 NREM sleep; $\square$ : stages 3 and 4 NREM sleep; $\boldsymbol{\Delta}$ : REM sleep. Note that increases in $(f R)$ resulted in increases in effective $V^{\prime} \mathrm{E}$ in a large majority of subjects during both wakefulness and sleep. For definitions see legend to figure 1. For explanation of steps, see table 1, and for significance of changes, see text. 
patient that we took care of) and November 1995 (the last patient that started home ventilation before the end of our experimental study). Twenty three out of 33 patients were given nIPPV during the night only, and 10 patients for the night and also a few hours during the day. In the large majority of cases, ventilator settings remained unchanged throughout the follow-up period. Exceptionally, minor adjustments were subsequently executed. Sleep architecture for 17 of these patients, untreated and under nIPPV, has been published elsewhere [17].

None of the patients needed oxygen supplementation during home ventilation. Two patients died after 9 months of long-term ventilation. Four patients were admitted to hospital (from 2-10 days) during follow-up because of bronchial infections (two patients), pulmonary embolism (one patient), and hypercapnic respiratory failure (the only COPD patient). None of these four patients needed to be admitted into the intensive care unit. Followup data were collected until January 1996.

Ventilator settings and follow-up. Table 4 shows the median and mean \pm SD of ventilator settings and followup during nIPPV for the group of patients. There was a large variability in delivered $f \mathrm{R}, V \mathrm{~T}$ (expressed either in absolute terms or per kilogram of body weight) and delivered $V^{\prime}$ 'I. In all these indices, the range of values used in patients encompassed the "best" values found in healthy subjects, and the mean values for the patient group were surprisingly close to the "best" values in healthy subjects.

\section{Discussion}

The development of nIPPV has facilitated the use of long-term mechanical ventilation in stable patients with respiratory failure. Its usefulness seems well established [19], but is not without exceptions [6]. With respect to assisted ventilation in intubated or tracheotomized patients, nIPPV faces a unique differential feature: a supplementary variable resistance, represented by the glottis, is interposed between the ventilator and the lungs. Several years ago, we observed central apnoeas in a patient with respiratory failure secondary to a myopathy (i.e. no respiratory motion of the thorax) despite correct delivery of positive pressure strokes by a volumetric ventilator. We were able to reproduce this finding in four out of five patients, and postulated that these apnoeas were not primarily due to leaks, but to complete glottic closure, resulting in secondary leaks [8]. Recent data in normal subjects seems to confirm our hypothesis that the glottis is the main hindrance to air flowing into the lungs, to the point of being able to completely occlude the airway, at least when using the controlled ventilatory mode [9-11]. Leaks are one of the main problems related to inefficacy during nIPPV therapy. Air can leak between the mask and the skin, or through the mouth. These leaks may be associated with a high $P$ mask, for instance when subject and ventilator are uncoordinated, or with a low Pmask, when the muscles controlling the velolingual and lip sphincters fail to provide an airtight seal. However, mouth leaks may also be secondary to high pharyngeal pressures, for instance during complete glottic closure $[9,10]$. These may be defined as exter-
Table 4. - Ventilator settings and follow-up for the group of patients, and "best" ventilator settings in healthy subjects, during sleep

\begin{tabular}{|c|c|c|c|}
\hline & \multicolumn{2}{|c|}{ Patients } & \multirow{2}{*}{$\begin{array}{l}\text { Healthy } \\
\text { subjects }\end{array}$} \\
\hline & Median & Mean \pm SD & \\
\hline$f_{\mathrm{R}}$ breaths $\cdot \mathrm{min}^{-1}$ & 24 & $\begin{array}{l}23 \pm 3.6 \\
(15-30)\end{array}$ & $\begin{array}{c}23 \\
(20-27)\end{array}$ \\
\hline Delivered $V \mathrm{~T} \quad \mathrm{~mL}$ & 630 & $\begin{array}{c}666 \pm 197 \\
(300-1300)\end{array}$ & \\
\hline$V \mathrm{~T} \quad \mathrm{~mL} \cdot \mathrm{kg}^{-1}$ & 13.3 & $\begin{array}{l}14 \pm 3.6 \\
(8-27)\end{array}$ & $\begin{array}{c}13 \\
(10-16)\end{array}$ \\
\hline$t \mathrm{I} \quad \mathrm{s}$ & 1.5 & $\begin{array}{c}1.3 \pm 0.2 \\
(1.0-2.0)\end{array}$ & \\
\hline$t \mathrm{E} \mathrm{s}$ & 1.5 & $\begin{array}{c}1.3 \pm 0.2 \\
(1.0-2.0)\end{array}$ & \\
\hline Delivered $V^{\prime} \mathrm{I} \quad \mathrm{L} \cdot \mathrm{s}^{-1}$ & 0.51 & $\begin{array}{c}0.51 \pm 0.15 \\
(0.24-0.95)\end{array}$ & $\begin{array}{c}0.76 \\
(0.56-0.85)\end{array}$ \\
\hline Devliered $V^{\prime} \mathrm{E} \mathrm{L} \cdot \mathrm{min}^{-}$ & -115.4 & $\begin{array}{l}15.5 \pm 0.7 \\
(7.2-28.6)\end{array}$ & $\begin{array}{c}20 \\
(17-23)\end{array}$ \\
\hline Follow-up yrs & 2.8 & $\begin{array}{c}3.2 \pm 2.2 \\
(0.2-8.2)\end{array}$ & \\
\hline
\end{tabular}

Data are presented as median, mean $\pm \mathrm{SD}$, and range in parenthesis for the patients, and for healthy subjects as mean, and range in parenthesis. $t \mathrm{I}$ : inspiratory time; $t \mathrm{E}$ : expiratory time. For further definitions, see legend to table 1.

nal leaks. Another possibility to be considered is the presence of internal leaks: air entering the oesophagus and stomach rather than the trachea, or air being accommodated in the compliant upper (pharyngeal) airway acting as a shunt compliance [20]. The amount of leaks will depend to a great extent on upper airway pressure, which in turn will partly depend on glottic resistance or, in other words, on glottic narrowing in response to nIPPV. The glottic response to assisted ventilation depends partly on the partial pressure of $\mathrm{CO}_{2}\left(\mathrm{PCO}_{2}\right)$ levels, and also on such mechanical factors as delivered $V$ T and $V^{\prime}$ I $[9,10]$. Choosing the right settings of the ventilator may thus, be the key to successful ventilation. Our previous studies were based on direct observation of the glottis with a fibreoptic bronchoscope at the expense of sleep quality [9-11]. Since the phenomenon of glottic closure during nIPPV is now well established, the present investigation could be carried out without direct observation of the glottis. This allowed a much better sleep quality, and a much larger volume of data to be analysed, with more experimental changes in ventilator settings. Thus, we could systematically explore the effects of changes in delivered $V^{\prime}$ I, delivered $V$ T and delivered $f \mathrm{R}$ on effective $V^{\prime} \mathrm{E}$ (due to the glottic response to nIPPV). We chose to study healthy subjects, based on the (albeit unproven) assumption that the key to a high effective $V^{\prime} \mathrm{E}$ lies on the glottis, and not on thoracopulmonary mechanics. However, to verify whether our observations apply to patients, we performed a retrospective analysis of ventilator settings in a group of patients submitted to long-term nIPPV.

Our present experimental data confirm the suggestions that mechanical factors can influence effective ventilation through an effect on the glottis. We found that increases in delivered $V^{\prime}$ I resulted, up to a certain level, in significant increases in effective ventilation reaching the lungs (fig. 1), whereas further increases in delivered $V^{\prime}$ I did not result in significant changes in $V^{\prime} E$. Our computation of $R$ I showed that airflow resistance decreased with moderate increases in delivered $V^{\prime}$ I. Further 
increases in delivered flow resulted in an increase (or in no further decrease) in $R \mathrm{I}$ in almost every subject. We interpret these findings as an indication of glottic widening, then narrowing, in response to changes in delivered $V^{\prime}$ I, leading to the observed changes in calculated $R$ I. Flow and temperature receptors are known to exist at the laryngeal level. Cooling of the larynx is known to decrease laryngeal resistance in cats [21], but to increase laryngeal resistance in dogs [22]. Progressive increases in flow (i.e. decreases in inspiratory time) may more or less overcome the temperature conditioning capacity of the nose, resulting in progressive levels of cooling of the airstream reaching the larynx. This could explain the decrease in $R \mathrm{I}$ with "modest" increases in $V^{\prime}$ I and the subsequent increase in $R$ I with large increase in $V^{\prime}$ I. Alternatively, the response to increases in flow may result from changes in airway pressure likely to result from shortening of $t$ I for a constant delivered $V \mathrm{~T}$. Pressure receptors are also known to exist in the larynx and their response to negative pressure has been studied. Contrary to our observations, sleep reduces the laryngeal response to application of negative pressure in the airway [23]. Positive pressure is known to be a less intense stimulus than negative pressure [24]. Therefore we favour flow and/or temperature, rather than pressure, receptors as responsible for the effects of changes in delivered $V^{\prime}$ I on the glottis and effective ventilation.

For a constant delivered $V^{\prime} \mathrm{I}$ and $V^{\prime} \mathrm{E}$, increases in delivered $V \mathrm{~T}$ of $310 \mathrm{~mL}$ resulted in average increases in $V \mathrm{~T}$ of $110 \mathrm{~mL}$ during wakefulness and $70 \mathrm{~mL}$ during sleep. These increases were insufficient to fully compensate for the decrease in frequency necessary to maintain the same delivered $V^{\prime} E$. As a consequence, $V^{\prime} E$ decreased significantly. We suggest that volume receptors reacting to an increase in lung volume induced glottic narrowing and attenuated the distension of the lungs. Volume information can be originated in slowly adapting receptors from the lung [25], in joint receptors from the thorax [26] or in intercostal muscles receptors [27]. Any or all of these receptors could have mediated the glottic response we postulate, in response to increases in delivered $V \mathrm{~T}$.

Increases in delivered $f \mathrm{R}$ resulted in a significant increase in effective ventilation in a large majority of subjects during both wakefulness and sleep (fig. 4). For the group as a whole, effective ventilation significantly increased when delivered $f \mathrm{R}$ increased from 15 to 20 and 15 to 27 but not from 20 to 27 breaths $\cdot \mathrm{min}^{-1}$. This was due to a decrease in $V \mathrm{~T}$ at a $f \mathrm{R}$ of 27 breaths. $\mathrm{min}^{-1}$, that was not compensated for by the increase in $f R$. Since delivered $V^{\prime} \mathrm{I}$ and $V$ T were maintained constant, flow and volume receptors are unlikely to explain these results, which could have been mediated by the decrease in $\mathrm{CO}_{2}$ at the highest ventilation.

The average results found in the group of patients look surprisingly close to the "ideal" settings in normals. It should be remembered that the criteria used to set the ventilators in patients were completely different from those used in the present experimental study. However, since part of the criteria used in patients depended on effective ventilation $\left(\mathrm{Sa}_{\mathrm{a}} \mathrm{O}_{2}\right.$ and reduction or suppression of respiratory muscle EMG signals), ventilator settings necessarily had to circumvent the glottic obstacle. Glottic response to nIPPV is probably similar in normals and patients [8-10]. Inasmuch as respiratory system mechan- ics are quite abnormal in patients with restrictive ventilatory defects (schematically through a decrease in thoracic compliance), the similarity of ventilator settings can be explained by a predominant role of the glottis (with respect to a lesser role of respiratory mechanics) in determining $V^{\prime} E$ during nIPPV. The variability of settings in patients should not be surprising, considering the age and body size range of our group of patients.

Previous reports of nIPPV in patients, using volumetric ventilators, seldom give the ventilator settings used $[1,28,29]$. We ignore the practical importance of this matter (looking for the highest possible $V^{\prime} \mathrm{E}$ ) on the final outcome (survival and decreased hospital admissions). However, it seems logical to aim at the highest $V^{\prime} \mathrm{E}$ for clinical use of nIPPV, in order to increase arterial oxygen tension $\left(\mathrm{Pa}_{\mathrm{a}} \mathrm{O}_{2}\right)$ (without oxygen supplementation) and to decrease $\mathrm{PCO}_{2}$. Leger et al. [28] used a lower delivered $f \mathrm{R}$ and a higher $V \mathrm{~T}$ than the present data, and $60 \%$ of their patients with kyphoscoliosis needed oxygen addition to keep the partial pressure of oxygen $\left(\mathrm{PO}_{2}\right)$ at acceptable levels.

A final consideration concerns the influence of sleep on the glottis. We previously observed that, for a given ventilator setting, $V^{\prime} E$ was systematically lower during sleep than during wakefulness [10]. This was also generally the case in this investigation. However, some exceptions existed (fig. 4). We had shown that sleep enhances glottic narrowing, to which we had attributed the lower ventilation during sleep [10]. We do not believe that the exceptions observed in the present study detract from our hypothesis. Rather, we think that the exceptions are due to excessive glottic narrowing during wakefulness, beyond the levels that could be accounted for by mechanical and $\mathrm{CO}_{2}$ factors. This hypothetical excessive glottic narrowing may be the result of cortical conscious influences that disappear during sleep. Our data in normals confirm that glottic response to nIPPV is influenced by sleep. Interestingly, the $V^{\prime} \mathrm{E}$ level observed in our ventilated healthy asleep subjects in stages 3-4 NREM sleep is similar to the one found by STRADLING et al. [30] in spontaneously breathing asleep normal subjects. This suggests that adjustment of ventilator settings in patients should be performed, as we usually do, during sleep, especially if patients are to use their ventilators during sleep, as is the general practice.

Despite the increasingly widespread clinical use of nasal intermittent positive pressure ventilation, this is, to the best of our knowledge, the first study to examine the best way to circumvent the problems posed by the glottic response to nasal ventilation. In summary, our data show that during nIPPV therapy, both in wakefulness and sleep, increases in effective ventilation should be obtained by increases in delivered respiratory frequency rather than in delivered tidal volume, but keeping mean delivered inspiratory flow close to physiological levels. Effective ventilation is lower during sleep than during wakefulness in a large majority of subjects. We suggest that during nIPPV performed with volumetric ventilators in patients with restrictive ventilatory defects, the initial settings should be: a delivered respiratory frequency of 20 breaths $\cdot \mathrm{min}^{-1}$, a delivered tidal volume of $13 \mathrm{~mL} \cdot \mathrm{kg}^{-1}$ and a delivered inspiratory flow lower than $0.9 \mathrm{~L} \cdot \mathrm{s}^{-1}$. This is quite different from the "standards" recommended in intubated patients. 
Acknowledgements: The authors acknowledge M.P. Biettlot for preparation of the figures and M. Boulangier for secretarial assistance.

\section{References}

1. Ellis ER, Bye PT, Bruderer JW, et al. Treatment of respiratory failure during sleep in patients with neuromuscular disease. Positive-pressure ventilation through a nose mask. Am Rev Respir Dis 1987; 135: 148-152.

2. Strumpf DA, Millman RP, Carlisle CC, et al. Nocturnal positive-pressure ventilation via nasal mask in patients with severe chronic obstructive pulmonary disease. Am Rev Respir Dis 1991; 144: 1234-1239.

3. Brochard L, Mancebo J, Wysocki M, et al. Noninvasive ventilation for acute exacerbations of chronic obstructive pulmonary disease. $N$ Engl J Med 1995; 333: 817-822.

4. Ambrosino N, Nava S, Bertone P, et al. Physiologic evaluation of pressure support ventilation by nasal mask in patients with stable COPD. Chest 1992; 101: 385-391.

5. Hubmayr RD. Setting the ventilator. In: Tobin MJ, eds. Principles and Practice of Mechanical Ventilation. 6. Setting the ventilator. New York, McGraw Inc., 1994; pp. 191-206.

6. Raphael JC, Chevret S, Chastang C, et al. Randomised trial of preventive nasal ventilation in Duchenne muscular dystrophy. French Multicentre Cooperative Group on Home Mechanical Ventilation Assistance in Duchenne de Boulogne Muscular Dystrophy. Lancet 1994; 343: 1600-1604.

7. Muntoni F, Hird M, Simonds AK. Preventive nasal ventilation in Duchenne muscular dystrophy. Lancet 1994; 344: 340.

8. Delguste P, Aubert-Tulkens G, Rodenstein DO. Upper airway obstruction during nasal intermittent positive-pressure hyperventilation in sleep. Lancet 1991; 338: 1295-1297.

9. Jounieaux V, Aubert G, Dury M, et al. Effects of nasal positive-pressure hyperventilation on the glottis in normal awake subjects. J Appl Physiol 1995; 79: 176-185.

10. Jounieaux V, Aubert G, Dury M, et al. Effects of nasal positive-pressure hyperventilation on the glottis in normal sleeping subjects. J Appl Physiol 1995; 79: 186-193.

11. Parreira VF, Jounieaux V, Aubert G, et al. Nasal twolevel positive-pressure ventilation in normal subjects. Effects on the glottis and ventilation. Am J Respir Crit Care Med 1996; 153: 1616-1623.

12. Rodenstein DO, Stanescu D, Delguste P, et al. Adaptation to intermittent positive pressure ventilation applied through the nose during day and night. Eur Respir $J$ 1989; 2: 473-478.

13. Rodenstein DO, Cuttitta G, Stanescu DC. Ventilatory and diaphragmatic EMG changes during negative-pressure ventilation in healthy subjects. J Appl Physiol 1988; 64: 2272-2278.

14. Rechtschaffen A, Kales A. A Manual of Standardized Terminology, Techniques, and Scoring System for Sleep Stages of Human Subjects. Los Angeles, UCLA, 1968.
15. Chadha TS, Watson H, Birch S, et al. Validation of respiratory inductive plethysmography using different calibration procedures. Am Rev Respir Dis 1982; 125: 644-649.

16. Gonzalez H, Haller B, Watson HL, et al. Accuracy of respiratory inductive plethysmograph over wide range of rib cage and abdominal compartmental contributions to tidal volume in normal subjects and in patients with chronic obstructive pulmonary disease. Am Rev Respir Dis 1984; 130: 171-174.

17. Collard P, Dury M, Delguste P, et al. Movement arousals and sleep-related disordered breathing in adults. Am J Respir Crit Care Med 1996; 154: 454-459.

18. Godfrey K. Statistics in practice. Comparing the means of several groups. N Engl J Med 1985; 313: 1450-1456.

19. Hill NS. Noninvasive positive pressure ventilation in neuromuscular disease. Enough is enough! Chest 1994; 105: 337-338.

20. Parreira VF, Delguste P, Jounieaux V, et al. Glottic aperture and effective minute ventilation during nasal two-level positive pressure ventilation in spontaneous mode. Am J Respir Crit Care Med 1996; 154: 1857-1863.

21. Jammes Y, Barthelemy P, Delpierre S. Respiratory effects of cold air breathing in anesthetized cats. Respir Physiol 1983; 54: 41-54.

22. Ukabam CU, Knuth SL, Bartlett D Jr. Phrenic and hypoglossal neural responses to cold airflow in the upper airway. Respir Physiol 1992; 87: 157-164.

23. Issa FG, Edwards P, Szeto E, et al. Genioglossus and breathing responses to airway occlusion: effect of sleep and route of occlusion. J Appl Physiol 1988; 64: 543549.

24. Hwang JC, St. John WM, Bartlett D Jr. Receptors responding to changes in upper airway pressure. Respir Physiol 1984; 55: 355-366.

25. van Lunteren E, Strohl KP, Parker DM, et al. Phasic volume-related feedback on upper airway muscle activity. J Appl Physiol 1984; 56: 730-736.

26. Bolser DC, Lindsey BG, Shannon R. Respiratory pattern changes produced by intercostal muscle/rib vibration. J Appl Physiol 1988; 64: 2458-2462.

27. Shannon R, Bolser DC, Lindsey BG. Medullary neurons mediating the inhibition of inspiration by intercostal muscle tendon organs? J Appl Physiol 1988; 65: 24982505.

28. Leger P, Bedicam JM, Cornette A, et al. Nasal intermittent positive pressure ventilation. Long-term followup in patients with severe chronic respiratory insufficiency. Chest 1994; 105: 100-105.

29. Barbe F, Quera-Salva MA, Lattre J, et al. Long-term effects of nasal intermittent positive-pressure ventilation on pulmonary function and sleep architecture in patients with neuromuscular disease. Chest 1996; 110: $1179-1183$.

30. Stradling JR, Chadwick GA, Frew AJ. Changes in ventilation and its components in normal subjects during sleep. Thorax 1985; 40: 364-370. 